\title{
Examining Success Factors in Deprescribing Proposals from Community Pharmacists
}

Shin Osada ( $\square$ adgjadgj78910@gmail.com )

Nihon-Chouzai Koiwa Minamiguchi Pharmacy

\section{Research Article}

Keywords: deprescription,polypharmacy, pharmacist, prescribing doctor.

Posted Date: July 6th, 2021

DOI: https://doi.org/10.21203/rs.3.rs-566959/v1

License: (c) (i) This work is licensed under a Creative Commons Attribution 4.0 International License. Read Full License 


\section{Abstract}

Background: Polypharmacy is a critical issue that affects elderly people in particular. In Japan, fees to support deprescription are calculated bycommunity pharmacists who propose deprescribing 2 or more medications for patients prescribed 6 or more. However, the fees are rarely calculated.The objective of this study is toexamine success factors in deprescribing proposals submitted bycommunity pharmacists to prescribing doctors.

Methods: Tracing reports submitted from Aug 2017 to Mar 2020 were investigated retrospectively to uncover factors that influenced the success of deprescribing using statisticalanalyses.

Results:One hundred and twenty-three unique tracing reports were submitted to the prescribing doctors. Of these, 67 reports were successful in deprescribing and 56 failed; the success rate was $54.5 \%$. Deprescribing proposals with existingunused medications significantly increased the deprescribing success rate. Possible adverse events, potentially inappropriate medications, and overlapping medications with the same effecttended to increase the success rate, but not significantly. Whether the pharmacist experienced face-to-face communication with the prescribing doctors did not significantly influence the outcome.

Conclusions:Tracing reports with deprescribing proposals submitted by community pharmacists may help resolve problems arising frompolypharmacy. Mentioning unused medications could increase the deprescribing success rate.

\section{Trial registration:}

This study did not registered due to purely observational study.

\section{Background}

Polypharmacy is one of the most critical healthcare issues worldwide, especially for elderly people. Elderly people prescribed five or more medications have a significantly increased fall risk and those prescribed six or more medications have a significantly increased risk of adverse events. ${ }^{[1]-[4]}$ Furthermore, some reports have suggested that polypharmacy can be defined as not only the number of medications used but also the use of medications that are not required or cause adverse events, regardless of the number. ${ }^{[5],[6]}$ Polypharmacy may also contribute to newly diagnosed dementia ${ }^{[7]}$ and cognitive decline. ${ }^{[8]}$ Pharmacists can play an important role for polypharmacy. For example, hospital pharmacists review inappropriate medications ${ }^{[9]-[11]}$ and community pharmacists screen inappropriate medications and consult prescribing doctors. ${ }^{[9]}$

In Japan, community pharmacists are required to communicate with other healthcare professionals, such as medical doctors, nurses, and nursing care managers. ${ }^{[12]}$ The Ministry of Health, Labour and Welfare recommends that healthcare professionals communicate with each other regarding services that incur 
fees in certain circumstances. In recent years fees have been established for a number of services as calculated by community pharmacists, being those who are primarily involved in identifying needs and communicating changes to doctors and other healthcare professionals. For example, fees to avoid overlapping medications or drug interactions $(2012)^{[13]}$, fees for submitting information regarding taking medication (2014) $)^{[14]}$, fees for supporting taking medications for outpatients $(2014)^{[14]}$, and fees for family pharmacists to give drug administration guidance (2016) ${ }^{[15]}$. Furthermore, fees to support deprescription were established in $2018^{[16]}$. The community pharmacists submit deprescribing proposal documents to prescribing doctors in patients prescribed six or more oral medications over 4 weeks. As a result of the proposals, two or more medications are withdrawn over 4 weeks and the fees can be calculated. Although fees to submit information regarding taking medication in Japan were calculated 30,567 times during the 2018 fiscal year, fees to support deprescription were calculated only 189 times. [17]

Fees to submit information regarding taking medication can be calculated not only by sending tracing reports to the prescribing doctors but also by consultations via telephone, letter, face-to-face interactions, or other methods with patients or healthcare professionals ${ }^{[12]}$. The proportion of fees regarding taking medication within tracing reports is not disclosed, meaning that exact numbers of tracing reports submitted to doctors in Japan is unclear. In addition, tracing reports can be included not only in deprescription proposals but also when mentioning unused medications, potential adverse events, adherence of patients, medications prescribed by other medical institutions, over-the-counter medications and so on. Nevertheless, it seems that deprescribing proposals via documents submitted from community pharmacists to prescribing doctors are rarely successful. ${ }^{[17]}$ The factors that influence the success rate of deprescribing proposals are still unknown. Thus, in this study, we investigated these factors using documents submitted by community pharmacists to prescribing doctors. We reveal success factors for deprescribing proposals that may help increase their success rate and resolve issues associated with polypharmacy.

In this study, we sought to identify success factors in deprescribing proposals from community pharmacists to prescribing doctors.

\section{Methods}

\section{Study design}

Study design: From Jul 2017 to Mar 2020, tracing reports submitted by pharmacists in Nihon Chouzai Koiwa-Minamiguchi Pharmacy were investigated retrospectively. As fees to submit information regarding taking medication were established in Apr 2014, we have sent tracing reports toward prescribing doctors since Jul 2017. Thus, the study period commenced from Jul 2017. Deprescription success was defined as not only a reduction in the number of prescribed oral medications but also a reduction in the dose. Potential inappropriate prescriptions were based on the "Guidelines for Medical Treatment and its Safety 
in the Elderly 2015," published by the Japan Geriatrics Society. ${ }^{[3]}$ Family pharmacists are defined as those identified by the patients who consent to have a family pharmacist, and extra fees are calculated for the family pharmacist. Possible adverse events were defined as reactions that the pharmacist suspected to occur as a result of taking medications and which were mentioned in the tracing reports. Overlapping medications with the same effect were based on a category of Today's Therapeutic Medications 2020 published by Nankodo Co., Ltd. ${ }^{[18]}$ "Pharmacist experienced face-to-face communication" was defined as the pharmacist experiencing face-to-face communication with the prescribing doctor.

Information was collected and analyzed for different factors that may contribute to the success or failure of the deprescription proposal.

Participants: Patients who were prescribed multiple medications by medical institutions, such as hospitals and clinics, and received their prescription at Nihon Chouzai Koiwa-Minamiguchi Pharmacy were included. All patients consented to the submission of the tracing reports, including the deprescribing proposal on oral medication, to prescribing doctors. For cases in which multiple reports were submitted to the prescribing doctor, a single report was included in the analysis. In these cases, deprescribing proposals that were successful were preferentially included over earlier, unsuccessful proposals due to the existence of some cases that repeated the same proposals that had been successful for deprescribing. Patients who did not visit the pharmacy after the submission of the tracing reports and those with tracing reports that included deprescribing proposals on external medications were excluded.

\section{Data collection}

The data in this survey were collected from tracing reports submitted by Nihon Chouzai KoiwaMinamiguchi Pharmacy to prescribing doctors. The reports submitted not only included cases who received their prescription at Nihon Chouzai Koiwa-Minamiguchi Pharmacy but also cases who received their prescription at other pharmacies and checked their prescribed medications at Nihon Chouzai KoiwaMinamiguchi Pharmacy using the patient's medication record booklet. For all reports, information on age, sex, number of oral medications prescribed, dosing frequency per day, presence or absence of potentially inappropriate prescriptions, having a family pharmacist, one-dose packages, unused medications, possible adverse events, overlapping same-effect medications, the pharmacist experiencing face-to-face communication, and whether deprescription proposals succeeded or not, was collected.

\section{Statistical analysis}

To identify the factors associated with success in the reduction of medication after the prescribing doctor received tracing reports from community pharmacists, univariate analyses were performed using logistic regression analysis. Furthermore, a multivariate logistic regression analysis was performed using the patient attributes with a $P$ value of less than 0.20 in the univariate analyses as covariates based on a previous study. ${ }^{[4]}$ In logistic regression analysis, a P-value, odds ratio and 95\% confidence interval (95\% 
$\mathrm{Cl}$ ) were calculated. A P-value of less than 0.05 indicated a factor that significantly influenced the success of deprescription from the tracing report submitted by community pharmacists. All analyses were performed using EZR software (version 1.50, Japan). ${ }^{[19]}$

\section{Results}

From Jul 2017 to Mar 2020, 637 tracing reports were submitted by the Nihon Chouzai KoiwaMinamiguchi Pharmacy to different medical institutions, including hospitals and clinics. Of these, 177 included deprescribing proposals. Patients consented to the submission of the reports to prescribing doctors in 149 of 177 cases. Cases in which multiple reports were submitted to the prescribing doctor, a single report was included in the analysis. Finally, 123 tracing reports that included deprescribing proposals were analyzed (Fig. 1). Deprescription succeeded in 67 cases and failed in 56 cases. The deprescription success rate was $54.5 \%$

In the univariate analysis, the P-values of sex, potential inappropriate prescriptions, family pharmacists, unused medications, possible adverse events, and overlapping same effective medications were less than 0.2. Therefore, these endpoints were analyzed using multivariate logistic regression analysis (Table 1). Comparing the successful deprescribing group vs the unsuccessful deprescribing group, covariates of average age (76.0 years old vs 76.2 years old, odds ratio: 0.999$)$, average number of oral medications prescribed ( 8.2 medications vs 7.8 medications, odds ratio: 1.03$)$, average dosing frequency per day (3.6 times vs 3.3 times, odds ratio: 1.14 ), \% of one-dose packages ( $32.8 \%$ vs $26.8 \%$, odds ratio: 1.34 ), and \% of "pharmacist experienced face-to-face communication" ( $76.1 \%$ vs $66.1 \%$, odds ratio: 1.64$)$ indicated a P-value $>0.2$ and were not included in the multivariate analysis. Meanwhile, sex (\% of male) ( $35.8 \%$ vs $51.8 \%$, odds ratio: 0.52 ), \% of potential inappropriate prescriptions ( $64.2 \%$ vs $42.9 \%$, odds ratio: $2.39)$, \% of family pharmacists ( $70.1 \%$ vs $53.6 \%$, odds ratio: 2.04$)$, \% of unused medications $(61.2 \%$ vs $37.5 \%$, odds ratio: 2.63 ), \% of possible adverse events ( $73.1 \%$ vs $44.6 \%$, odds ratio: 3.38 ), and \% of overlapping same-effect medications ( $64.2 \%$ vs $42.9 \%$, odds ratio: 2.39 ) indicated a P-value $<0.2$ and were included in the multivariate analysis. 
Table 1

Results of univariate analysis performed for each endpoint

\begin{tabular}{|c|c|c|c|c|}
\hline & $\begin{array}{l}\text { Deprescribing } \\
\text { succeeded } \\
(n=67)\end{array}$ & $\begin{array}{l}\text { Deprescribing } \\
\text { failed } \\
(n=56)\end{array}$ & $\begin{array}{l}\text { Odds } \\
\text { ratio }\end{array}$ & $\begin{array}{l}\text { P-value of } \\
\text { univariate } \\
\text { analysis }\end{array}$ \\
\hline Average age & 76.0 & 76.2 & 0.999 & 0.966 \\
\hline $\begin{array}{l}\text { Average number of oral medications } \\
\text { prescribed }\end{array}$ & 8.2 & 7.8 & 1.03 & 0.51 \\
\hline Average dosing frequency per day & 3.6 & 3.3 & 1.14 & 0.32 \\
\hline Sex (\% of male, female) & $(35.8,64.2)$ & $(51.8,48.2)$ & 0.52 & 0.0764 \\
\hline $\begin{array}{l}\% \text { of potential inappropriate } \\
\text { medications }\end{array}$ & 64.2 & 42.9 & 2.39 & 0.019 \\
\hline$\%$ of family pharmacists & 70.1 & 53.6 & 2.04 & 0.06 \\
\hline$\%$ of one-dose packages & 32.8 & 26.8 & 1.34 & 0.467 \\
\hline$\%$ of unused medications & 61.2 & 37.5 & 2.63 & 0.00956 \\
\hline$\%$ of possible adverse events & 73.1 & 44.6 & 3.38 & 0.00158 \\
\hline $\begin{array}{l}\% \text { of overlapping same-effect } \\
\text { medications }\end{array}$ & 64.2 & 42.9 & 2.39 & 0.019 \\
\hline $\begin{array}{l}\% \text { of "pharmacist experienced face- } \\
\text { to-face communication" }\end{array}$ & 76.1 & 66.1 & 1.64 & 0.221 \\
\hline
\end{tabular}

In the multivariate analysis, the presence of unused medications (odds ratio: $3.21,95 \% \mathrm{Cl}$ : 1.4-7.38, Pvalue: 0.00593 ) significantly increased the deprescribing success rate (Table 2 , Fig. 2). In addition, sex (male) (odds ratio: $0.547,95 \% \mathrm{Cl}: 0.242-1.24$, P-value: 0.147 ), potential inappropriate medications (odds ratio: $1.75,95 \% \mathrm{Cl}$ : 0.738-4.13, P-value: 0.205 ), overlapping same-effect medications (odds ratio: 1.91, 95\% Cl: 0.839-4.37, P-value: 0.123), and possible adverse events (odds ratio: 2.55, 95\% Cl: 0.993-6.54, Pvalue: 0.0518 ) tended to increase the deprescribing success rate but not significantly. 
Table 2

Results of logistic regression analysis

\begin{tabular}{|c|c|c|c|c|}
\hline & $\begin{array}{l}\text { Odds } \\
\text { ratio }\end{array}$ & $95 \% \mathrm{Cl}$ & & $\begin{array}{l}\text { P-value of logistic regression } \\
\text { analysis }\end{array}$ \\
\hline Family pharmacists & 1.08 & 0.458 & 2.53 & 0.867 \\
\hline Unused medications & 3.21 & 1.4 & 7.38 & $0.00593^{\star \star}$ \\
\hline Sex (male) & 0.547 & 0.242 & 1.24 & 0.147 \\
\hline $\begin{array}{l}\text { Potential inappropriate } \\
\text { medications }\end{array}$ & 1.75 & 0.738 & 4.13 & 0.205 \\
\hline $\begin{array}{l}\text { Overlapping same-effect } \\
\text { medications }\end{array}$ & 1.91 & 0.839 & 4.37 & 0.123 \\
\hline Possible adverse events & 2.55 & 0.993 & 6.54 & 0.0518 \\
\hline
\end{tabular}

\section{Discussion}

Tracing reports that included deprescribing proposals, submitted by the pharmacists who worked at Nihon Chouzai Koiwa-Minamiguchi Pharmacy to the prescribing doctors, were investigated to search for the factors of success in deprescribing proposals. In this study, 67 of 123 proposals resulted in successful deprescription; the success rate was $54.5 \%$. Nevertheless, fees to support deprescription were calculated only 16 times by Nihon Chouzai Koiwa-Minamiguchi Pharmacy from Apr 2018 to Mar 2020. The reason for this gap is the different definition between deprescribing success in this study and the calculation requirements of fees to support deprescription. Definition of deprescribing success in this study is not only a reduction in the number of prescribed oral medications but also a reduction in the amount of dose of the prescribed oral medications without a reduction in the number of prescribed oral medications. Thus, the requirements for calculating the fees to support deprescription are: (1) the community pharmacists submit the deprescribing proposal documents to the prescribing doctors for patients prescribed six or more oral medications for 4 weeks, and (2) withdraw two or more medications in 4 weeks as a result of the proposal. The calculation requirements of fees to support deprescription is stricter than the definition of deprescribing success in this study. The results of this study suggest that tracing reports submitted by community pharmacists help to increase deprescribing practices. Previous studies have suggested that intervention for deprescribing reduces the number of prescribed medications. [20], [21] However, the success factors in deprescribing are still unknown and are revealed in this study for the first time. In this study, the existence of unused medications significantly increased the success rate. In addition, sex (female), potential inappropriate medications, overlapping same-effect medications, and possible adverse events tended to increase the deprescribing success rate but not significantly. 
The results of this study suggested that mentioning existing unused medications on tracing reports increased the success rate of the deprescribing proposals. It is reported that the value of unused medications is 650 billion Japanese yen per year. ${ }^{[22]}$ Existing unused medication is often the result of nonadherence. Nonadherence caused by difficulty in taking medication due to cognitive impairments, low level of education, ${ }^{[23]}$ or patients taking some kinds of medications on-demand. [24], [25] When pharmacists find unused medications, they can propose stopping the unused medications or reducing the daily dosing frequency to the prescribing doctor.

Pharmacists learn not only the efficacy and mechanisms of absorption, distribution, metabolism, and

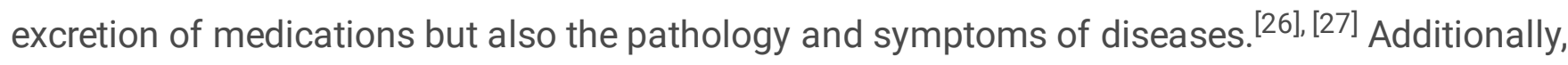
community pharmacists are aware of a patient's condition, worries, and lifestyle habits. Therefore, community pharmacists are in a position to assess potential inappropriate medications, overlapping

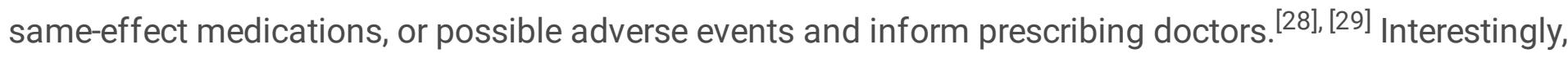
tracing reports submitted by pharmacists who had experienced face-to-face communication with the prescribing doctors did not significantly influence the deprescribing success rate, although a previous study mentioned that face-to-face communication with doctors is important for deprescribing. ${ }^{[30]}$ This difference may have occurred because the past study did not perform a quantitative evaluation, whereas this study did. Nihon Chouzai Koiwa-Minamiguchi Pharmacy receives prescriptions from more than 100 medical institutions. It is not practical to have face-to-face communication with all prescribing doctors. This study suggests that community pharmacists find unused medications and inform the prescribing doctor to help resolve polypharmacy.

Pharmaceutical intervention by the community pharmacists using tracing reports helps to resolve polypharmacy. Specifically, deprescribing proposals with information regarding unused medications should increase the deprescribing success rate.

This study included a small sample and tracing reports written by pharmacists at only one pharmacy. Additionally, most of tracing reports were written by one pharmacist. Furthermore, this study was retrospective. In the future, a prospective study with a large sample size involving multiple pharmacies should be conducted.

\section{Abbreviations}

$\mathrm{Cl}$, Confidence interval

\section{Declarations}

\section{Ethics approval and consent to participate}


This study was reviewed and approved by the research ethics committee of Nihon Chouzai Co., Ltd. (approval number: 2019-025, 26th Dec 2019). Due to anonymized data in a retrospective study, the research ethics committee of Nihon Chouzai Co., Ltd. has approved the acquisition of patient consent to submit tracing reports to the prescribed doctors instead of consent to participate. Methods were carried out in accordance with relevant guidelines (i.e., Ethical guidelines for epidemiological research ${ }^{[31]}$ ) and regulations.

\section{Consent for publication}

Not applicable.

\section{Competing interest}

The author declares no competing interests.

\section{Funding}

This research did not receive any specific grant from funding agencies in the public, commercial, or notfor-profit sectors.

\section{Authors' contribution}

Shin Osada played roles for wrote and submitted approximately $95 \%$ of tracing reports, made study design, collected data, inputted date, statistically analyzed, wrote manuscript and prepared all figures and tables.

\section{Acknowledgements}

I thank Dr. Hiroshi Okada, specially-appointed lecturer at Kyoto University School of public health for advising research theme and employee of Nihon Chouzai Co., Ltd. co-workers for submitting some tracing reports to the prescribing doctors.

\section{References}

1. Kojima T, Akishita M, Nakamura T, Nomura K, Ogawa S, lijima K,et al. Polypharmacy as a risk for fall occurrence in geriatric outpatients. GeriatrGerontol Int.2012;12:425-30.

2. Kojima T, Akishita M, Kameyama Y, Yamaguchi K, Yamamoto H, Eto M,et al. High risk of adverse drug reactions in elderly patients taking six or more drugs: analysis of inpatient database. GeriatrGerontol 
Int.2012;12:761-2.

3. Guidelines for medical treatment and its safety in the elderly. 2015. https://www.jpn-geriatsoc.or.jp/info/topics/pdf/20170808_01.pdf. Accessed 23May 2021.

4. Imai H, Hirai T, Kumazawa R, Nakagawa S, Yonezawa A, Matsubara K, Nakao H, et al.Prevalence of and risk factors for adverse events in Alzheimer's patients receiving antidementia drugs in at-home care. PLOS One. 2020;15:e0231226..

5. Masnoon N, Shakib S, Kalisch-Ellett L, Caughey GE. What is polypharmacy? A systematic review of definitions. BMC Geriatr.2017;17:230.

6. Mortazavi SS, Shati M, Keshtkar A, Malakouti SK, Bazargan M, Assari S. Defining polypharmacy in the elderly: a systematic review protocol.BMJ Open. 2016;6:e010989.

7. Park HY, Park JW, Song HJ, Sohn HS, Kwon JW. The association between polypharmacy and dementia: A nested case-control study based on a 12-year longitudinal cohort database in South Korea. PLOS One. 2017;12:e0169463.

8. Ishii N, Mochizuki H, Sakai K, Ogawa G, Shiomi K, Nakazato M. Polypharmacy associated with cognitive decline in newly diagnosed Parkinson's disease: A cross-sectional study. Dement GeriatrCogn Dis Extra. 2019;9:338-43.

9. Suzuki $S$, Uchida $M$, Suga $Y$, Sugawara $H$, Kokubun $H$, Uesawa $Y$,et al. A nationwide survey of community pharmacist contributions to polypharmacy in opioid-using and non-using cancer patients in Japan. Biol Pharm Bull.2019;42:1164-71.

10. Uchida M, Suzuki S, Sugawara H, Suga Y, Kokubun H, Uesawa Y,et al. A nationwide survey of hospital pharmacist interventions to improve polypharmacy for patients with cancer in palliative care in Japan.J Pharm Health Care Sci.2019;5:14.

11. Onda M, Imai H, Takada Y, Fujii S, Shono T, Nanaumi Y.Identification and prevalence of adverse drug events caused by potentially inappropriate medication in homebound elderly patients: a retrospective study using a nationwide survey in Japan. BMJ Open. 2015;5:e007581.

12. The Ministry of Health, Labor and Welfare. Pharmacy vision for patients. https://www.mhlw.go.jp/file/04-Houdouhappyou-11121000-lyakushokuhinkyokuSoumuka/gaiyou_1.pdf. Accessed 23May 2021.

13. The Ministry of Health, Labor and Welfare. Outline of 2012 medical fee revision. https://www.mhlw.go.jp/bunya/iryouhoken/iryouhoken15/dl/gaiyou.pdf. Accessed 23May 2021.

14. The Ministry of Health, Labor and Welfare. Outline of 2014 medical fee revision. https://www.mhlw.go.jp/file/06-Seisakujouhou-12400000-Hokenkyoku/0000039891.pdf. Accessed 23May 2021.

15. The Ministry of Health, Labor and Welfare. Outline of 2016 medical fee revision. https://www.mhlw.go.jp/file/06-Seisakujouhou-12400000-Hokenkyoku/0000115977.pdf. Accessed 23May 2021.

16. The Ministry of Health, Labor and Welfare. Outline of 2018 medical fee revision. https://www.jadia.or.jp/pdf/tokuteigaiyou.pdf. Accessed 23May 2021. 
17. The Ministry of Health, Labor and Welfare. 2018 fiscal year statistics by medical practice. https://www.mhlw.go.jp/content/12404000/000547022.pdf. Accessed 23May 2021.

18. Urabe A, Shimada K, Kawai S. Today's Therapeutic Medications2020 Published by Nankodo Co., Ltd.

19. Kanda, Y. Investigation of the freely available easy-to-use software 'EZR' for medical statistics. Bone Marrow Transplant.2013;48:452-8.

20. 20. Edelman $M$, Jellema $P$, Hak E, Denig P, Blanker MH. Patients' attitudes Towards deprescribing alpha-blockers and their willingness to participate in a discontinuation trial. Drugs Aging. 2019;36:1133-9.

21. 21. van der Meer HG, Wouters H, Teichert M, Griens F, Pavlovic J, Pont LG, et al. Feasibility, acceptability and potential effectiveness of an information technology-based, pharmacist-led intervention to prevent an increase in anticholinergic and sedative load among older communitydwelling individuals. Ther Adv Drug Saf.2019;10:2042098618805881.

22. Masuyama, K. A study on the impact of remaining drugs on medical insurance finance and measures to eliminate it. https://www.mhlw.go.jp/file/05-Shingikai-12404000-HokenkyokuIryouka/0000103268.pdf. Accessed 23May 2021.

23. García S, Martínez-Cengotitabengoa M, López-Zurbano S, Zorrilla I, López P, Vieta E,et al. Adherence to antipsychotic medication in bipolar disorder and schizophrenic patients: A systematic review. $J$ Clin Psychopharmacol.2016;36:355-371.

24. Sinnige J, Korevaar JC, van Lieshout J, Westert GP, Schellevis FG, Braspenning JC. Medication management strategy for older people with polypharmacy in general practice: a qualitative study on prescribing behaviour in primary care. Br J Gen Pract. 2016;66:e540-51.

25. Farrell B, Pottie K, Thompson W, Boghossian T, Pizzola L, Rashid FJ,et al. Deprescribing proton pump inhibitors: evidence-based clinical practice guideline. Can Fam Physician. 2017;63:354-64.

26. The Ministry of Health, Labor and Welfare. Pharmacist national examination questioning criteria. https://www.mhlw.go.jp/file/06-Seisakujouhou-11120000-lyakushokuhinkyoku/H22kizyun.pdf. Accessed 23May 2021.

27. Keijsers CJ, Brouwers JR, de Wildt DJ, Custers EJ, Ten Cate OT, Hazen AC,et al.A comparison of medical and pharmacy students' knowledge and skills of pharmacology and pharmacotherapy. $\mathrm{Br} J$ Clin Pharmacol. 2014;78:781-8.

28. Morath B, Mayer T, Send AFJ, Hoppe-Tichy T, Haefeli WE, Seidling HM. Risk factors of adverse health outcomes after hospital discharge modifiable by clinical pharmacist interventions: a review with a systematic approach. Br J Clin Pharmacol.2017;83:2163-78.

29. Schiff GD, Klinger E, Salazar A, Medoff J, Amato MG, John Orav E,et al. Screening for adverse drug events: a randomized trial of automated calls coupled with phone-based pharmacist counseling. $J$ Gen Intern Med.2019;34:285-92.

30. Marvin V, Ward E, Jubraj B, Bower M, Bovill I. Improving pharmacists' targeting of patients for medication review and deprescription. Pharmacy (Basel). 2018;6:32. 
31. Ethical guidelines for epidemiological research. Partially revised on April 1, 2013 https://www.mhlw.go.jp/seisakunitsuite/bunya/hokabunya/kenkyujigyou/i-kenkyu/dl/0202.pdf.Accessed 23May 2021.

\section{Figures}

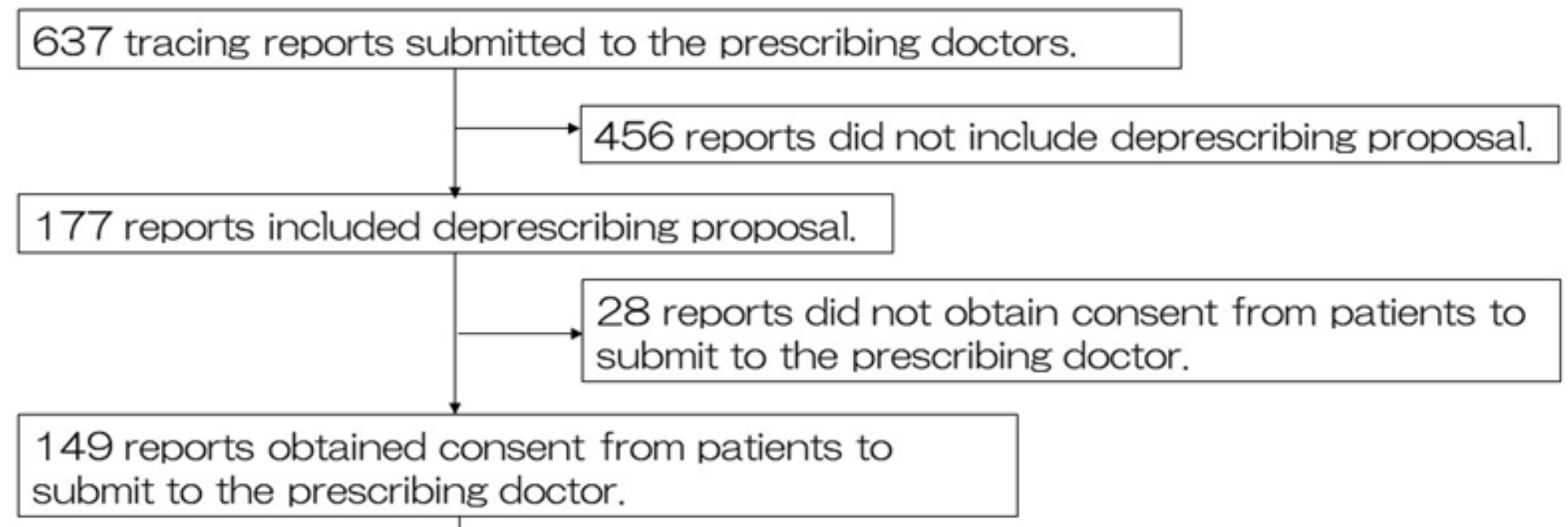

Cases in which multiple reports were submitted to - the prescribing doctor, a single report was including the analysis.

123 reports were analyzed in this study.

56 reports failed deprescribing.

67 reports succeeded deprescribing.

\section{Figure 1}

Criteria for selecting tracing reports and outcomes of analyzed reports. Flow chart describing selection of tracing reports for analysis, and final outcomes of analyzed reports. Of 123 analyzed tracing reports, 67 reports succeeded in deprescribing and 56 reports failed. 


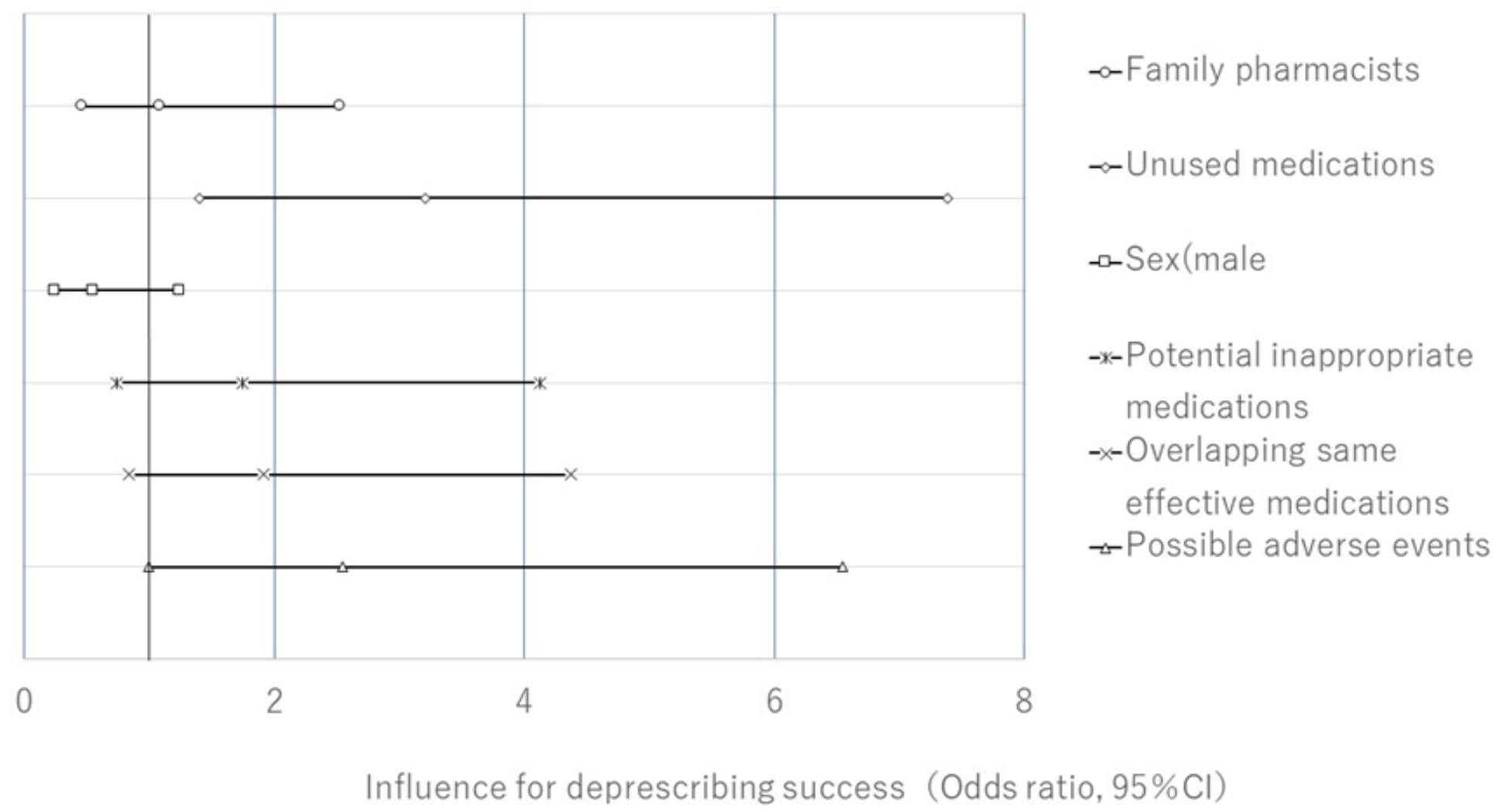

Figure 2

Forest plot of logistic regression analysis. The odds ratio was calculated and analyzed using EZR software (version 1.50, Japan). The symbols with line indicate the odds ratio with $95 \% \mathrm{Cl}$. The odds ratio of 1 indicates no difference in success rate of deprescribing proposal. An odds ratio $>1$ indicates an increased success rate of deprescribing proposal whereas an odds ratio $<1$ suggests a reduced success rate of deprescribing proposals. 